\title{
Correction to: The coming-of-age of nucleocytoplasmic transport in motor neuron disease and neurodegeneration
}

\author{
Paulo A. Ferreira ${ }^{1}$ (])
}

Published online: 28 March 2019

(c) Springer Nature Switzerland AG 2019

\section{Correction to: Cellular and Molecular Life Sciences https://doi.org/10.1007/s00018-019-03029-0}

The original version of this article unfortunately contained the following misspelling and formatting mistakes.

In the 3rd sentence under the section "An emerging and unifying principle in ALS", a word was incorrectly spelt. The correct sentence should read as follows:

Before expanding on some recent findings that lend support to this principle, these developments are encumbered with their own intricate constraints and complexities that forces consideration of basic and current principles underpinning nucleocytoplasmic transport.
The original article can be found online at https://doi.org/10.1007/ s00018-019-03029-0.

Paulo A. Ferreira

paulo.ferreira@duke.edu

1 Duke University Medical Center, DUEC 3802, 2351 Erwin Road, Durham, NC 27710, USA
In the 9th sentence of the second paragraph under the section "Gle 1 and other nucleporinsins" formatting of a word was incorrect. The correct sentence should read as follows:

Finally, a novel intranuclear and long-lived Ranbp2 isoform, which is unique to spinal motoneurons, relocates to the cytosolic compartment where it localizes to the mitochondria after losses of Ranbp2 and of the short-lived Ranbp2 isoform at the nuclear pores [241].

Publisher's Note Springer Nature remains neutral with regard to jurisdictional claims in published maps and institutional affiliations. 